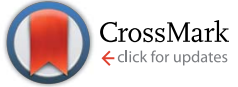

Cite this: RSC Adv., 2016, 6, 20644

Received 17th December 2015 Accepted 15th February 2016

DOI: $10.1039 / c 5 r a 27059 f$

www.rsc.org/advances

\section{High-flux affinity membranes based on cellulose nanocomposites for removal of heavy metal ions from industrial effluents $\uparrow$}

\begin{abstract}
Zoheb Karim, ${ }^{\text {ae }}$ Aji P. Mathew, ${ }^{\text {*ab }}$ Vanja Kokol, ${ }^{c}$ Jiang Wei ${ }^{d}$ and Mattias Grahn ${ }^{e}$
Fully biobased affinity membrane processing and its application in the removal of heavy metal ions from mirror industry effluents were successfully demonstrated; indicating the potential use of these membranes in point-of-use or point-of-entry water cleaning products that are cheap, environmentally friendly and efficient. Layered cellulose nanocomposite membranes were fabricated using cellulose

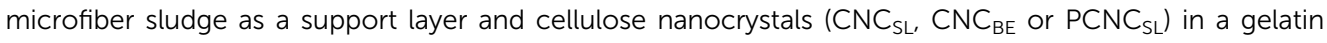
matrix as the functional layer. Scanning electron microscopy (SEM) studies revealed the bi-layered morphology of the membrane and well-individualized nanocelluloses in the functional layer. Bubble point measurements confirmed the membrane pore structure in the microfiltration range $(5.0-6.1 \mu \mathrm{m})$, which provided very high water permeability $\left(900-4000 \mathrm{~L} \mathrm{~h}^{-1} \mathrm{~m}^{-2}\right)$ at $<1.5$ bars. A tensile strength of $16 \mathrm{MPa}$ in dry conditions and a wet strength of $0.2 \mathrm{MPa}$, was considered sufficient for use of these membranes in spiral wound modules. Mirror industry effluent laden with metal ions $\left(\mathrm{Ag}^{+}\right.$and $\mathrm{Cu}^{2+} / \mathrm{Fe}^{3+} /$ $\mathrm{Fe}^{2+}$ ) when treated with cellulose nanocomposite membranes, showed high ion removal capacity, being $100 \%$ for $\mathrm{PCNC}_{\mathrm{SL}}$ followed by $\mathrm{CNC}_{\mathrm{BE}}$ than $\mathrm{CNC}_{\mathrm{SL}}$. The removal of metal ions was expected to be driven by interactions between negatively charged nanocellulose and the positively charged metal ions.
\end{abstract}

\section{Introduction}

Over the past two decades, environmental regulations have become more stringent on heavy metal concentrations, which demand improved and innovative water treatment technologies. In recent years, a wide range of treatment technologies such as chemical precipitation, coagulation-flocculation, flotation, ion exchange and conventional membrane filtration, have been developed for heavy metal removal from contaminated wastewater. However, no individual treatment has been found to be universally effective and applicable for heavy metals removal. Furthermore, drawbacks such as high operational costs due to the chemicals used, high-energy consumption, handling costs for sludge disposal and high pressure for

${ }^{a}$ Division of Materials Science, Luleå University of Technology, 97187, Luleå, Sweden. E-mail: aji.mathew@ltu.se; aji.mathew@mmk.su.se; Fax: +46 92049 1399; Tel: +46 920492024

${ }^{b}$ Department of Materials and Environmental Chemistry, Stockholm University, 10691 Stockholm, Sweden

${ }^{c}$ University of Maribor, Institute for Engineering Materials and Design, Smetanova ulica 17, SI-2000 Maribor, Slovenia

${ }^{d}$ Alfa Laval Nakskov A/S, Business Center Membranes, Stavangervej 10, DK-4900, Nakskov, Denmark

${ }^{e}$ Department of Civil, Environmental and Natural Resources Engineering, Division of Sustainable Process Engineering, 97187, Luleå, Sweden

$\dagger$ Electronic supplementary information (ESI) available. See DOI: $10.1039 / \mathrm{c} 5 \mathrm{ra} 27059 \mathrm{f}$ filtration are also noticed. ${ }^{\mathbf{1 , 2}}$ It is important to note that the selection of the most suitable treatment for metalcontaminated wastewater depends on the initial metal concentration, the overall treatment performance compared to other technologies, plant flexibility/reliability and environmental impact. All the factors mentioned above should be taken into consideration in selecting the most effective and inexpensive treatment in order to protect the environment.

Recently, nanostructured affinity membranes were developed for the removal/rejection of contaminants based on physical/chemical properties or biological functions. ${ }^{3-5}$ Rather than operating purely on the sieving mechanism, adsorption membrane based on the selectivity of the membrane to 'capture' contaminants, by immobilizing specific ligands or specific functional groups onto the surface of membranes. Affinity membrane reflects technological advances in both fixed-bed liquid separation and membrane filtration, and combines both the outstanding selectivity and the reduced pressure drops associated with filtration membranes. ${ }^{5}$

Micro-nano structure poly(ether sulfones)/poly(ethyleneimine) nanofibrous membrane fabricated by Chu and coworkers from Stony Brook University with nanocrystals as functional additives have show remarkable adsorption for anionic dyes and heavy metal ions from aqueous solution., ${ }^{4,5}$ Our recent studies have shown that nanocellulose in native form or with additional surface functionalization (tempo oxidation, enzymatic phosphorylation, cationization etc.) have significant adsorption 
efficiency towards metal ions, nitrates, dyes, humic acid etc. from industry effluents. ${ }^{6-9}$ However the challenge is to find suitable processing methods to fabricate membranes using nanocellulose to obtain optimal adsorption, mechanical stability and flux with out compromising on the green image of 'nanocellulose'. Karim et $a .^{8}$ have previously showed that cellulose nanocrystals based membranes prepared by freeze drying resulted in low water flux and low mechanical performance, in spite of good functionality. Low mechanical properties was attributed to the processing method used, viz. freeze-drying, which reduces H-bonding between nanocrystals and low flux was to the high thickness $(250 \mu \mathrm{m})$ of membrane.

In the present study, an improved fully bio-based high flux membrane-(membranes/adsorbents) was fabricated using very simple and fast process, viz. vacuum filtration followed by hot pressing, following the 'nanopaper approach'. ${ }^{\mathbf{1 0 , 1 1}}$ We have recently shown that nanopaper from native or cationically functionalized nanocellulose can effectively remove metal ions, nitrates, etc. ${ }^{12,13}$ However the tight network of nanofibers resulted in lower flux $\left(5-50 \mathrm{~L} \mathrm{~m}^{-2} \mathrm{~h}^{-1} \mathrm{bar}^{-1}\right)$, which needs improvement. Therefore in the current study a thin layer of native and modified cellulose nanocrystals was used as functional entity on a support layer of microsized cellulose fibers to fabricate a fully bio-based membrane. It was expected that the networking potential of microscale fibers can be combined with adsorption potential of nanocellulose to tailor efficient water cleaning membranes. The support layer of cellulose sludge micro fibers cuts down the cost of membranes/adsorbents, but provides mechanical and dimensional stability due to $\mathrm{H}^{-}$ bonding. Impregnation of the support layer with nanocrystals provide a functional surface for the membrane, tailorable based on the surface functionality of cellulose nanocrystals. The morphology of the membranes and dispersion on nanoparticles in the functional layer was studied SEM images. Mechanical testing was performed in dry as well as in wet conditions using tensile testing machine. Flux was measured by cross-flow filtration device equipped with temperature and pressure control. To the best of our knowledge, no reports are available on the processing of layered affinity membranes based on cellulosic paper for the removal of metal ions from water. The adsorption performance was evaluated using two real wastewater samples containing $\mathrm{Ag}^{+}$and $\mathrm{Cu}^{2+} / \mathrm{Fe}^{3+} / \mathrm{Fe}^{2+}$ from mirror industry were collected from southern part of Europe (Spain) and discussed with respect to adsorption mechanism as well as performance compared to adsorbent materials available in market.

\section{Experimental}

\subsection{Materials}

Non-dried dissolving cellulose residue (sludge) from dissolving cellulose was obtained from Domsjö Fabriker AB, Ornskoldsvik mill, Sweden. Sludge was used as received without any pretreatments. Based on the data from the material supplier, the chemical composition of the used sludge was, cellulose content (95\%), hemicellulose $(4.75 \%)$ and very low content of lignin.
Gelatin and polyethylene glycol (PEG 2000) were purchase from Sigma-Aldrich (USA). Acetic acid and sulfuric acid were supplied by VWR (BDH, France).

\subsection{Isolation and surface modification of nanocellulose}

The process routes used to prepare cellulose nanocrystals used in the study as functional entity are schematically shown in Fig. 1. Cellulose nanocrystals $\left(\mathrm{CNC}_{\mathrm{SL}}\right)$ were isolated from cellulose sludge using sulphuric acid hydrolysis as reported by Karim et al. ${ }^{\mathbf{2}}$

Cellulose nanocrystal were also prepared using bioethanol pilot plant process. Unbarked wood was hydrolyzed using dilute acid in a bioethanol pilot plant and refined by solvent extraction and bleaching to obtain pure cellulose. Cellulose, after bioethanol process in a plant was supplied by SP Processum, Örnsköldsvik, Sweden (17 wt\%). The purified cellulose from bioethanol process was made into $2 \mathrm{wt} \%$ suspensions, mixed by shear mixture and passed through the homogenizer, 10 times to obtain a thick gel of cellulose nanocrystals $\left(\mathrm{CNC}_{\mathrm{BE}}\right)$ as reported earlier by Mathew et al. ${ }^{14}$

The $\mathrm{CNC}_{\mathrm{SL}}$ were enzymatically modified to introduce phosphoryl groups on the surface reaction was carried out accordingly to Bozic et al. ${ }^{15}$ Briefly, reaction proceed in $0.9 \mathrm{wt} \%$ of $\mathrm{CNC}_{\mathrm{SL}}$ phosphate buffer ( $\mathrm{pH}$ 7.6) dispersion in the presence of a $50 \mathrm{mM}$ ATP, $250 \mathrm{mM}$ of $\mathrm{MgCl}_{2}$ and $35 \mathrm{U} \mathrm{ml}^{-1}$ of hexokinase enzyme for $24 \mathrm{~h}$ at $30^{\circ} \mathrm{C}$. After the protein deactivation, $\mathrm{PCNC}_{\mathrm{SL}}$ were washed several times (centrifuged at $6000 \mathrm{rpm}$ for $4 \mathrm{~min}$ ) with distilled water, until no ATP absorption peak at $260 \mathrm{~nm}$ could be detected.

Fig. 1 shows the AFM images of the used cellulose nanocrystals in the membrane fabrication. $\mathrm{CNC}_{\mathrm{SL}}$ (Fig. 1a) and $\mathrm{CNC}_{\mathrm{BE}}$ (Fig. 1b) shows typical cellulose nanocrystal structure and the diameters were found to be in the range of 5-10 $\mathrm{nm}$. AFM image of $\mathrm{PCNC}_{\mathrm{SL}}$ (Fig. 1c) have whisker like structures but

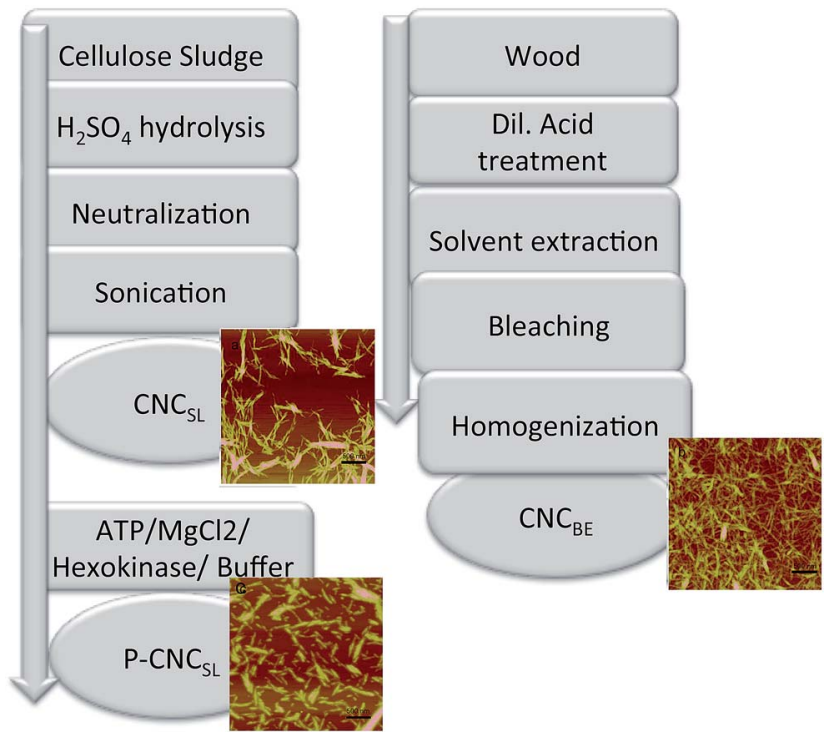

Fig. 1 Isolation processes of functional entities and the morphology based on atomic force microscopy. 


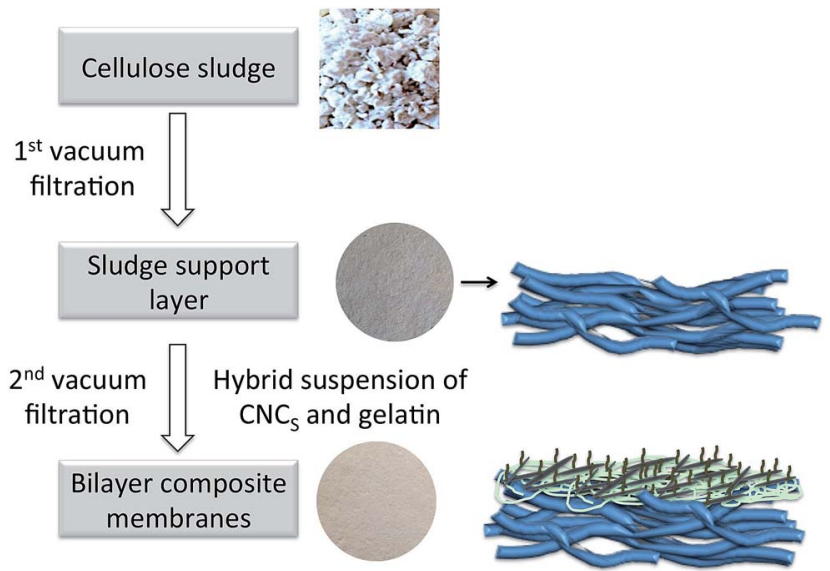

Fig. 2 Fabrication process of layered cellulose nanocomposite membranes using vacuum-filtration process.

were shorter and broader than the corresponding non-modified ones. The diameters were found to be in the range of $20 \mathrm{~nm}$, indicating the presence of laterally aggregated CNCs after drying on mica surfaces. The diameters reported are based on the height to compensate the tip broadening effect and were measured using Nanoscope $\mathrm{V}$ software. The accurate determination of the length was not possible from the AFM using this method and therefore not presented here. However, the AFM image shows that $\mathrm{CNC}_{\mathrm{BE}}$ are longer compared to $\mathrm{CNC}_{\mathrm{SL}}$ and $\mathrm{PCNC}_{\mathrm{SL}}$.

\subsection{Processing and characterization of membranes/ adsorbents}

A very simple and fast method, vacuum-filtration was used to prepare thin-layered cellulose nanocomposite membranes. 2 wt $\%$ of sludge was used to form the support layer. The fabrication of the thin functional layer was performed by further filtration of nanocellulose $\left(\mathrm{CNC}_{\mathrm{BE}}, \mathrm{CNC}_{\mathrm{SL}}\right.$ and $\left.\mathrm{PCNC}_{\mathrm{SL}}\right)$-gelatin suspension as shown in Fig. 2. Nanocellulose suspensions and gelatin ( $1 \mathrm{wt} \%$ each) were taken in $1: 1$ ratio to form the functional layer. After $12 \mathrm{~h}$ of drying in room-temperature, the prepared membranes were pressed between aluminium plates in a compression-molding machine with load of $60-70 \mathrm{kN}$ (Fontune Presses, Elastocon, Sweden) with heating $\left(80^{\circ} \mathrm{C}\right)$ to obtain compacted membranes.

\section{Characterization methods}

\subsection{Microscopy}

An atomic force microscope (Nanoscope V, Veeco Instruments, Santa Barbara, CA, USA) was used to examine the morphologies of the functional nanomaterials. The cantilever resonance frequency and the spring constant were $350 \mathrm{kHz}$ and $10-200$ $\mathrm{nm}^{-1}$, respectively for measurement. The diameter measurements were conducted with the aid of Nanoscope $\mathrm{V}$ software.

The membranes fractured in liquid nitrogen and sputter coated with tungsten were observed in the SEM (MAGELLAN
400, SEM, FEI Company) at an acceleration voltage of $3 \mathrm{kV}$ to understand the morphology and nanostructure.

\subsection{Mechanical properties}

The tensile tests of the layered cellulose nanocomposite membranes in dry as well as in wet condition were performed, using a Universal Testing Machine, Shimadzu Autograph AG-X (Japan), with a load cell of $1 \mathrm{kN}$ and the gauge length was 20 $\mathrm{mm}$ and width on $5 \mathrm{~mm}$.

\subsection{Pore size, porosity and BET surface area}

The average pore size was measured for $\mathrm{CNC}_{\mathrm{BE}}$ and $\mathrm{PCNC}_{\mathrm{SL}}$ membranes using bubble point method using PMI Capillary Flow Porometer from porous Materials, Inc. USA.

Porosity of the samples was determined by the mercury intrusion technique using an AutoPore III mercury porosimeter (Micromeritics Instrument Co.). The membranes cut into a rectangular shape $(1 \times 2 \mathrm{~cm})$ was weighed and used for the study.

Surface area of the membranes was determined using $\mathrm{N}_{2}$ adsorption following Brunauer-Emmett-Teller (BET) method using (Micromeritics ASAP 2020) automated system.

\subsection{Measurement of water permeability}

Sludge support and $\mathrm{CNC}_{\mathrm{BE}}$ and $\mathrm{PCNC}_{\mathrm{SL}}$ based membranes were used for the measurement of water permeability. A schematic diagram of the experimental apparatus for a cross-flow filtration test is presented in Fig. 3. The total surface area of membrane used was approximately $0.0169 \mathrm{~m}^{2}$, which was sufficiently compared with the working volume of feed water. The water permeability of membranes was determined up to burst pressure (1.5 bar) starting from 0.5 bars.

\subsection{Evaluation of heavy metals adsorption}

Two wastewater samples from mirror making industry, contaminated with $\mathrm{Ag}^{+}$and a mixture of $\mathrm{Cu}^{2+} / \mathrm{Fe}^{3+} / \mathrm{Fe}^{2+}$ were obtained from southern part of Europe were used for the adsorption experiments. The pHs of effluents contaminated

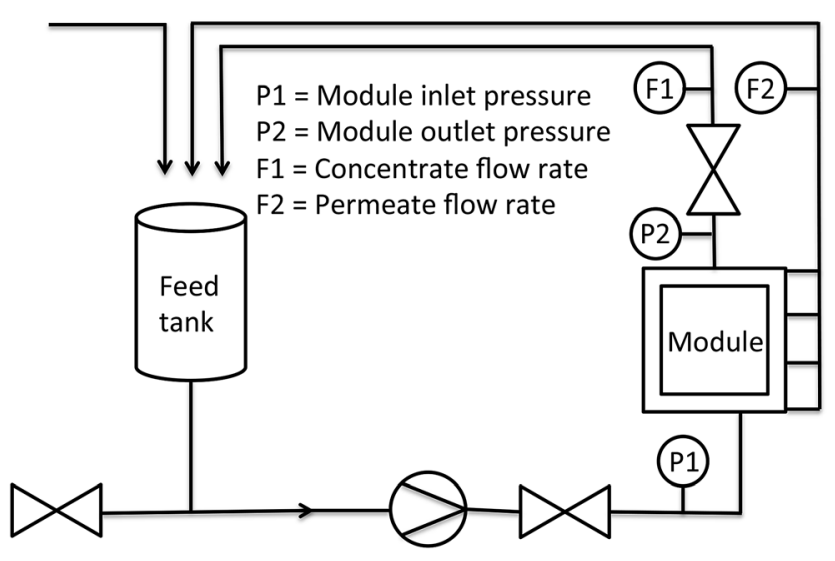

Fig. 3 Cross-flow filtration system scheme. 
with $\mathrm{Ag}^{+}$and $\mathrm{Cu}^{2+} / \mathrm{Fe}^{3+} / \mathrm{Fe}^{2+}$ were 9.1 and 2.3 , respectively (see ESI $\mathrm{S} 1 \uparrow$ for the typical composition of the used water sample).

All membranes were places in dead end cell apparatus and $50 \mathrm{ml}$ of polluted water was filled and passed through the porous membranes at 4.5 bars of applied pressure. The ICP-OES was used to measure the ions concentration before and after treatment. Control experiment was also performed with sludge/ gelatin nanocomposite membrane. The adsorption capacity of membranes for ions was calculated as described below. ${ }^{7}$

$$
C_{\mathrm{o}}-C_{\mathrm{i}} \times V / W
$$

where; $C_{\mathrm{o}}$ and $C_{\mathrm{i}}$ are initial and reaming conc. of metal ions in $\mathrm{mg} \mathrm{L}{ }^{-1}, V$ is used volume in litres and $W$ is membrane weight in grams.

Metals ions, adsorbed on nanocomposite membranes were further characterized using a scanning electron microscope (SEM, JSM-6460 LV, JEOL, USA), equipped with energy dispersive X-ray elemental spectrometry (EDS), having software, Inca Energy, Oxford. The adsorbed membranes were scanned with the depth of around $2 \mu \mathrm{m}$ to detect the presence of metal ions. The electron beam of $20 \mathrm{kV}$ was applied to determine the presence of ions.

\subsection{Membrane stability/biodegradability}

Bi-layered membranes having $\mathrm{CNC}_{\mathrm{BE}}$ as functional layer and cellulose sludge as support layer $\left(\mathrm{S}-\mathrm{G} / \mathrm{CNC}_{\mathrm{BE}}\right)$ were dipped in water having different $\mathrm{pH}$ values $(2.3,6.9$ and 9.2$)$ at $37^{\circ} \mathrm{C}$. Real wastewater of pHs 2.3 and 9.2 described under section 3.5 and tap water at $\mathrm{pH} 6.9$ were used. In a parallel experiment, membranes were embedded in soil at different temperature values $\left(5,25\right.$ and $\left.37{ }^{\circ} \mathrm{C}\right)$. In order to determine the stability/ degradability, membranes were removed from water or soil and weighed at different time intervals for a period of 6 months. Degradation rate percentage was calculated with respect to control membranes weight, taken as $100 \%$. The weight loss of treated membranes was measured after $24 \mathrm{~h}$ drying at room temperature. All samples were imaged using a digital camera to visually compare the degradation.

\section{Results and discussion}

\subsection{Micro-nano scaled structure of layered membranes}

The thickness of the support layer was measured to be $430 \mu \mathrm{m}$ (determined by digital calipers), which increased to 440-448 $\mu \mathrm{m}$, after the impregnation with the functional layer. The thickness of functional layer of $\mathrm{CNC}_{\mathrm{SL}}, \mathrm{CNC}_{\mathrm{BE}}$, and $\mathrm{PCNC}_{\mathrm{SL}}$ determined based on the thickness difference were 10, 18 and $11 \mu \mathrm{m}$, respectively. The thickness difference for the functional layers may be assigned to the dimensions of nanocrystals and the relative degree of impregnation of gelatin/CNC suspension into the support layer.

The morphology of the support and the layered nanocomposite membranes at the micro/nanometer length scale were observed using SEM and are shown in Fig. 4. In Fig. 4a the surface and the cross-section of the support layer are given where microsized fibers were clearly visible and the fibers were loosely bound together in a 3D network, with micro-scaled voids in between.

The bi-layered membrane cross-sections for S-G/CNC $\mathrm{CL}_{\mathrm{SL}}, \mathrm{S}-\mathrm{G} /$ $\mathrm{CNC}_{\mathrm{BE}}, \mathrm{S}-\mathrm{G} / \mathrm{PCNC}_{\mathrm{SL}}$ are shown in Fig. $4 \mathrm{~b}-\mathrm{d}$. In all SEM images in the left column a surface functional layer is clearly visible on the support layer. However, the depth of impregnation varied from sample to sample and it was not possible to see any nanocrystals impregnated into the support layer at this magnification. SEM images in the middle column shows that the functional layer on the top was found to be made up of layered structures in all cases.

The images on the right column show the functional layer at high magnifications. The high-resolution SEM image of functional layer showed individualized nanoscaled dispersed within the gelatin forming a network of functional entity without visible agglomerates. The good dispersion of nanocrystals in gelatin matrix indicates positive interaction between gelatin matrix and nanocrystals. It may be considered that nanocrystals are bound together in a three-dimensional network by gelatin chains; and is represented schematically in Fig. 2. Further more, the functional layer also seems to be denser and the nanocrystals being more embedded in the matrix in the case of $\mathrm{CNC}_{\mathrm{BE}}$ compared to $\mathrm{CNC}_{\mathrm{SL}}$ and $\mathrm{PCNC}_{\mathrm{SL}}$. A lower degree of infusion (and probably film formation) was expected for $\mathrm{CNC}_{\mathrm{BE}}$ compared to $\mathrm{CNC}_{\mathrm{SL}}$ and $\mathrm{P}-\mathrm{CNC}_{\mathrm{SL}}$, due to the presence of longer nanocrystals and probably explain the higher thickness of the functional layer based on $\mathrm{CNC}_{\mathrm{BE}}$. The micro-scaled porosity of the support layer and low thickness of the functional layer confirmed by SEM was expected to provide high flux during water purification while providing sufficient mechanical strength.

The surface area as obtained from $\mathrm{BJH}$ analysis of $\mathrm{N}_{2}$ gas adsorption isotherm of $\mathrm{S}-\mathrm{G} / \mathrm{CNC}_{\mathrm{BE}}$ thin-layered nanocomposite membrane was highest $\left(32.6 \mathrm{~m}^{2} \mathrm{~g}^{-1}\right)$ compared to $\mathrm{S}-\mathrm{G} / \mathrm{CNC}_{\mathrm{SL}}$ membrane $\left(26.3 \mathrm{~m}^{2} \mathrm{~g}^{-1}\right)$ followed by S-G/PCNC $\mathrm{SL}\left(18.8 \mathrm{~m}^{2} \mathrm{~g}^{-1}\right)$ membranes. The lower surface area of all the fabricated membranes is expected due to the low surface area of the microscaled support as well as the compacting of networks (support and functional layers) during hot pressing. Another reason for the difference in the surface area may be the depth of infusion of nanocellulose within the support layer and is probably related to the dimensions of cellulose nanocrystals. The $\mathrm{CNC}_{\mathrm{BE}}$, system with lower degree of infusion, provided membranes with highest surface area.

\subsection{Mechanical properties}

Mechanical properties of layered cellulose nanocomposite membranes measured in tensile mode are summarized in Table 1. The support layer showed a strength of $9 \mathrm{MPa}$, which increased with the addition of the nanocrystalline functional layer. Higher strength of membranes was observed in the current study (13-19 $\mathrm{MPa}$ ) compared to our earlier studies on freeze-dried CNC based nanocomposites $(2 \mathrm{MPa})^{8}$ as well as the support used in this study. It was inferred that the filtration followed by hot pressing used for the preparation of membranes facilitate the formation of hydrogen bonds and 
a
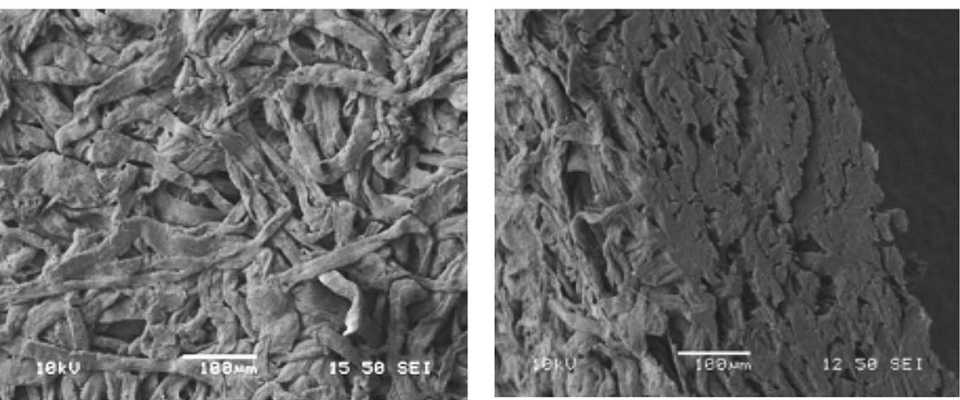

b
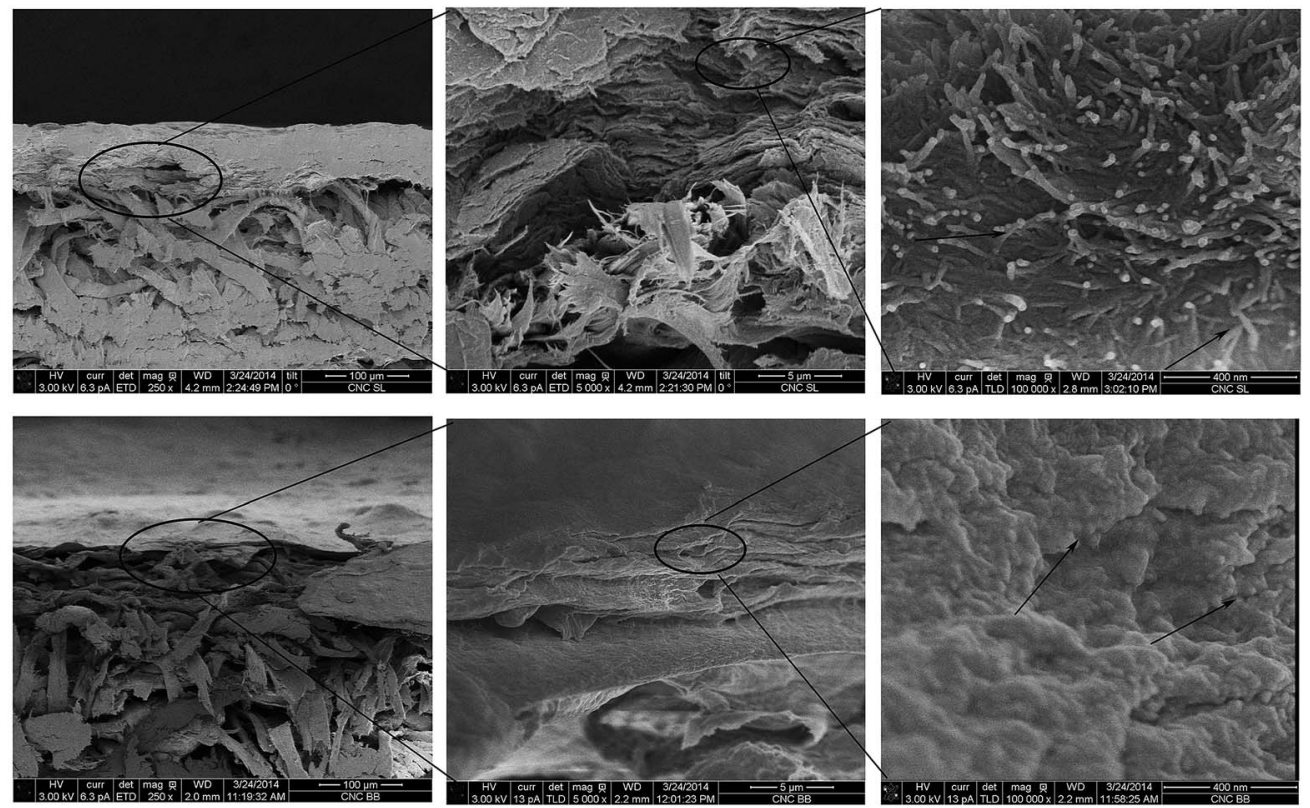

d
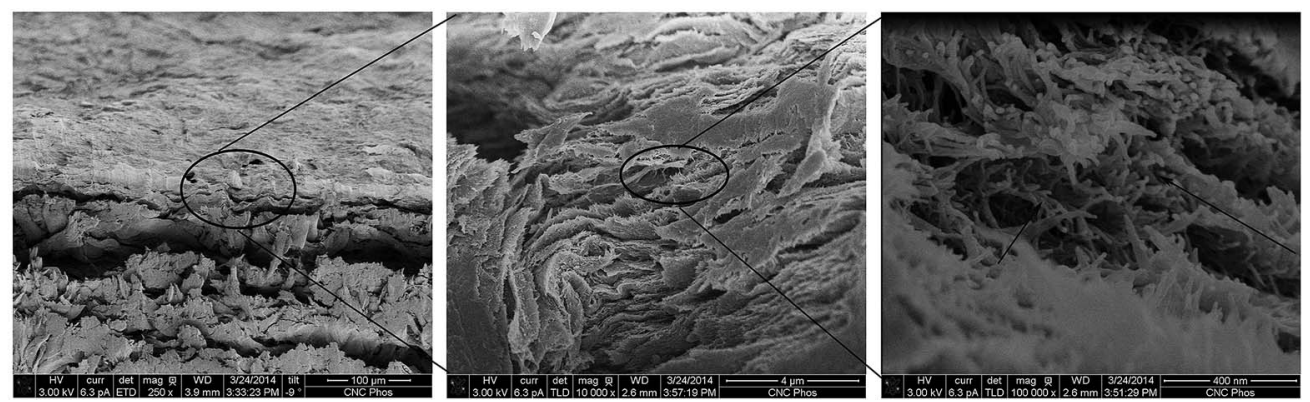

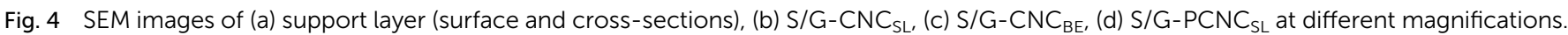

Table 1 Mechanical stability of nanocellulose membranes

\begin{tabular}{llccc}
\hline Conditions & Types of membranes & Modulus of elasticity (MPa) & Stress at break (MPa) & Max strain (\%) \\
\hline \multirow{2}{*}{ Dry } & Support & $245 \pm 0.1$ & $9 \pm 0.2$ & $13 \pm 0.3$ \\
& S-G/CNC & $362 \pm 0.3$ & $19 \pm 0.8$ & $2.1 \pm 0.3$ \\
& S-G/CNC & $647 \pm 0.4$ & $16 \pm 0.5$ & $2.3 \pm 0.1$ \\
& S-G/PCNC & $402 \pm 0.9$ & $0.13 \pm 0.4$ & $0.21 \pm 0.4$ \\
Wet & Support & $37 \pm 0.4$ & $0.24 \pm 0.5$ & $0.4 \pm 0.4$ \\
& S-G/CNC & $70 \pm 0.2$ & $0.22 \pm 0.6$ & $0.3 \pm 0.3$
\end{tabular}


thereby provide mechanical stability to the membranes. The tensile strength and the modulus of $\mathrm{CNC}_{\mathrm{BE}}$ based bi-layered membrane were higher compared to $\mathrm{CNC}_{\mathrm{SL}}$ and $\mathrm{PCNC}_{\mathrm{SL}}$ membranes. The strain at break was in the range of $2 \%$ and the differences between membranes were not statistically significant. Recently, ultrafiltration membrane with CNC infused on nonwoven support of electrospun PAN fibers was reported. Mechanical properties were measured and compared with commercial available GS0.22 ultrafiltration membrane; ${ }^{5}$ the stress at break of reported nanocomposite membrane was $14 \pm$ $0.8 \mathrm{MPa}$ and modulus was $375 \mathrm{MPa}$. The bi-layered membranes in the current study fabricated via vacuum filtration have comparable tensile strength and higher modulus. It is worth mentioning that in the current study the support layer is based on cheap bioresidue and the prepared membrane is fully biobased.

The mechanical stability in wet condition follows the same trend as shown in dry condition but with lower values. The higher mechanical properties on $\mathrm{CNC}_{\mathrm{BE}}$ based membranes may be due to the denser functional layer compared to $\mathrm{CNC}_{\mathrm{SL}}$ and $\mathrm{P}-$ $\mathrm{CNC}_{\mathrm{SL}}$ found in SEM studies. The reported tensile strength (even in wet condition) of all fabricated membranes was enough to use them in water cleaning application especially in spiral wound modules. ${ }^{16}$

\subsection{Pore structure and water permeability of nanocellulose based membranes}

Bubble point method is a very accurate and effective technique for pore size measurement at industrial level. The average pore size of the support was $6.6 \mu \mathrm{m}$ and decreased to 5.1 and $6.2 \mu \mathrm{m}$ for $\mathrm{S}-\mathrm{G} / \mathrm{CNC}_{\mathrm{BE}}$ and $\mathrm{S}-\mathrm{G} / \mathrm{PCNC}_{\mathrm{SL}}$ respectively; which confirmed the microfiltration range of nanocomposite membranes. The large average pore sizes of nanocomposite membranes are beneficial to ensure high flux through the membranes. The large distribution of pore sizes was however noticed and may require further process optimization to improve the pore homogeneity.

The porosity of the support layer (based on mercury porosimetry) was $69.48 \%$. Slightly decreased porosity was observed in the case of $\mathrm{S}-\mathrm{G} / \mathrm{PCNC}_{\mathrm{SL}}$ and $\mathrm{S}-\mathrm{G} / \mathrm{CNC}_{\mathrm{BE}}(\approx 65 \%)$. The results confirmed the presence of thin and denser functional layer of nanocrystals on the highly porous support layer. Thicker porous material is known to promote water movement in a zig-zag motion while linear motion has been observed within thinner materials. ${ }^{17,18}$

The water permeability of the nanocellulose based membranes was evaluated in cross-flow system for $\mathrm{S}-\mathrm{G} / \mathrm{CNC}_{\mathrm{BE}}$ and $\mathrm{S}-\mathrm{G} / \mathrm{PCNC}_{\mathrm{SL}}$ and compared with that of the support. Water flux experiments were conducted under the variable rate condition (applied pressure) and Fig. 5 shows the water permeability data as a function of applied pressure during cross-flow. The water permeability was $3417 \mathrm{~L} \mathrm{~m}^{-2} \mathrm{~h}^{-1} \mathrm{bar}^{-1}$ for the support, which decreased to 950 and $2622 \mathrm{~L} \mathrm{~m}^{-2} \mathrm{~h}^{-1}$ bar $^{-1}$ respectively for $\mathrm{S}-\mathrm{G} / \mathrm{CNC}_{\mathrm{BE}}$ and S-G/PCNC $\mathrm{SL}$. Ma et al. ${ }^{5}$ had reported that the flux through a microfiltration membrane using CNCs as infused entity within PAN nanofibrous scaffold

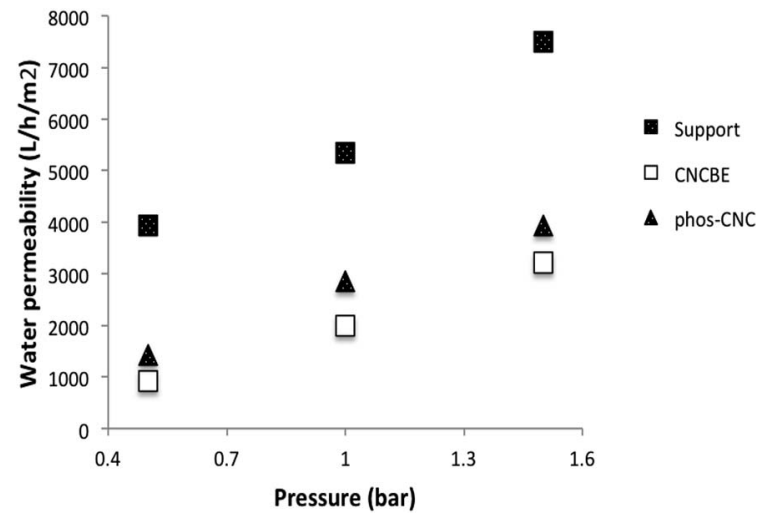

Fig. 5 Water permeability of layered cellulose nanocomposite membranes with different pressures.

was $0.59 \mathrm{~L} \mathrm{~m}^{-2} \mathrm{~h}^{-1} \mathrm{bar}^{-1}$ and much higher than commercial membrane, GS0.22 (0.25 $\left.\mathrm{L} \mathrm{m}^{-2} \mathrm{~h}^{-1} \mathrm{bar}^{-1}\right)$. Fabricated layered cellulose nanocomposite affinity membranes in the current study therefore have significantly higher flux compared to previously reported membranes as well as the commercially available membranes. Also the flux reported in the current study is higher than all our earlier reports where a single thicker layer nanocellulose was used for membrane application..$^{8,11,12}$

The support layer showed the highest water permeability at all applied pressure owing to the free water flow through microstructure and decreased when the functional layer is present. The water permeability of $\mathrm{S}-\mathrm{G} / \mathrm{CNC}_{\mathrm{BE}}$ is low at all applied pressures compared to $\mathrm{S}-\mathrm{G} / \mathrm{PCNC}_{\mathrm{SL}}$ and is probably due to denser film formation by $\mathrm{CNC}_{\mathrm{BE}}$ on the support; which is supported by SEM studies. The low water flux of $\mathrm{CNC}_{\mathrm{BE}}$ based nanocomposite membranes was further supported by the average pore size results; being lowest for $\mathrm{S}-\mathrm{G} / \mathrm{CNC}_{\mathrm{BE}}$.

\subsection{Adsorption of metal ions in cross-flow mode}

The removal efficiency of $\mathrm{Ag}^{+}, \mathrm{Cu}^{2+}$ and $\mathrm{Fe}^{3+} / \mathrm{Fe}^{2+}$ ions from industrial effluent using the membranes were studied in crossflow mode and static mode (Table 2). Cross-flow mode of operation provides more surface area for adsorption in contrast with static mode operation due to high penetration power of pollutants and bulk adsorption possibility, therefore, it is considered to be the efficient mode while using at industrial level in real wastewater purification. The adsorption capacity in static mode is provided with in parenthesis for comparison.

In the case of $\mathrm{Ag}^{+}$, complete removal (100\%) was observed in all cases and was explained based on the low concentration of $\mathrm{Ag}^{+}$ions in the industrial effluent. The metal ions removal efficiency of all three nanocomposite functional membranes, is in the order of $\mathrm{PCNC}_{\mathrm{SL}}>\mathrm{CNC}_{\mathrm{BE}}>\mathrm{CNC}_{\mathrm{SL}}$ for $\mathrm{Cu}^{2+} / \mathrm{Fe}^{3+} / \mathrm{Fe}^{2+}$ water. The removal rate of $\mathrm{PCNC}_{\mathrm{SL}}$ functional membrane was the highest and varied between 74 and $86 \%$ for the metal ions. $\mathrm{CNC}_{\mathrm{BE}}$ nanocomposite membrane has intermediate removal capability, both for $\mathrm{Cu}^{2+}(36 \%)$ and $\mathrm{Fe}^{3+}(33 \%)$ compared to $\mathrm{CNC}_{\mathrm{SL}}$ functional nanocomposite membrane (only $13-14 \%$ for 
Table 2 The removal efficiency of $\mathrm{Ag}^{+}, \mathrm{Cu}^{2+}$ and $\mathrm{Fe}^{2+} / \mathrm{Fe}^{3+}$ ions from industrial effluent using the membranes in cross-flow mode and static mode. The adsorption capacity in static mode is provided with in parenthesis for comparison

\begin{tabular}{|c|c|c|c|c|c|c|}
\hline \multirow[b]{2}{*}{ Types of membranes } & \multirow[b]{2}{*}{$\mathrm{pH}$} & \multirow[b]{2}{*}{$C_{\mathrm{o}}\left(\mathrm{mg} \mathrm{L}^{-1}\right)$} & \multirow[b]{2}{*}{$C_{\mathrm{i}}\left(\mathrm{mg} \mathrm{L}^{-1}\right)$} & \multicolumn{2}{|l|}{ Sorption capacity } & \multirow[b]{2}{*}{ Removal rate $(\%)$} \\
\hline & & & & Membrane $\left(\mathrm{mg} \mathrm{g}^{-1}\right)$ & CNCs $\left(\mathrm{mg} \mathrm{g}^{-1}\right)$ & \\
\hline \multicolumn{7}{|l|}{$\mathrm{Cu}^{2+}$} \\
\hline $\mathrm{S}-\mathrm{G} / \mathrm{CNC}_{\mathrm{SL}}$ & 2.3 & 330.2 & 285 & $9.6(8)$ & $28(11)$ & $13 \%$ \\
\hline $\mathrm{S}-\mathrm{G} / \mathrm{CNC}_{\mathrm{BE}}$ & & & 211 & $24(22)$ & $67(64)$ & $36 \%$ \\
\hline $\mathrm{S}-\mathrm{G} / \mathrm{PCNC}_{\mathrm{SL}}$ & & & 43 & $79(66)$ & $358(233)$ & $86 \%$ \\
\hline \multicolumn{7}{|l|}{$\mathrm{Fe}^{3+} / \mathrm{Fe}^{2+}$} \\
\hline $\mathrm{S}-\mathrm{G} / \mathrm{CNC}_{\mathrm{SL}}$ & 2.3 & 550.5 & 472 & $16.7(14)$ & $48(20)$ & $14 \%$ \\
\hline $\mathrm{S}-\mathrm{G} / \mathrm{CNC}_{\mathrm{BE}}$ & & & 369 & $37(34)$ & $102(100)$ & $33 \%$ \\
\hline $\mathrm{S}-\mathrm{G} / \mathrm{PCNC}_{\mathrm{SL}}$ & & & 140 & $113(109)$ & $512(391)$ & $74 \%$ \\
\hline \multicolumn{7}{|l|}{$\mathbf{A g}^{+}$} \\
\hline $\mathrm{S}-\mathrm{G} / \mathrm{CNC}_{\mathrm{SL}}$ & 9.1 & 1.48 & 0.00 & $0.33(0.29)$ & $0.82(0.42)$ & $100 \%$ \\
\hline $\mathrm{S}-\mathrm{G} / \mathrm{CNC}_{\mathrm{BE}}$ & & & 0.00 & $0.33(0.29)$ & $0.87(0.87)$ & $100 \%$ \\
\hline $\mathrm{S}-\mathrm{G} / \mathrm{PCNC}_{\mathrm{SL}}$ & & & 0.00 & $0.33(0.29)$ & $0.81(1.00)$ & $100 \%$ \\
\hline
\end{tabular}

$\mathrm{Cu}^{2+}$ and $\mathrm{Fe}^{3+}$ ). Thus, the removal rate for $\mathrm{CNC}_{\mathrm{BE}}$ is two times higher with respect to $\mathrm{CNC}_{\mathrm{SL}}$.

The concentration of functional group on the surface of fabricated membranes is the reason for the different percentage removal. The sulphate groups present on the surface of $\mathrm{CNC}_{\mathrm{SL}}$ are $30-90 \mathrm{mmol} \mathrm{kg}^{-1}$ is lowest compare to carboxylic group on $\mathrm{CNC}_{\mathrm{BE}}\left(150 \mathrm{mmol} \mathrm{kg}^{-1}\right)$ and the highest value of carboxylic and phosphate groups (425 mmol $\mathrm{kg}^{-1}$ ) are recorded on phosphorylated CNC; therefore, phosphorylated CNC have highest removal percentage of metal ions compare to other used nanocelluloses. ${ }^{\mathbf{1 4 , 1 9}}$

In static mode also the removal behaviour follows the same trends for membranes as shown in static mode but the capacity is lower, in general, for all metal ions studied. It may be noted that the $\mathrm{pH}$ of effluent containing silver metal ions was 2.7 and copper/iron metal ions was 9.2, which confirms the effectiveness and versatility of the membranes in acidic as well as basic conditions. Further more the membranes were found to be efficient in different concentration ranges and for different metal ions, which can be of advantage in real applications.

$\mathrm{Cu}^{2+}$ adsorption from water based on literature reports (Table 3) shows that the best removal rate for chitosan with an efficiency of $70 \mathrm{mg} \mathrm{g}^{-118}$ on chitosan followed by carbon nanotube $\left(67.8 \mathrm{mg} \mathrm{g}^{-1}\right) .{ }^{19}$ Bio-based nanomaterials have also been used for the remediation of $\mathrm{Cu}^{2+}$; recently two reports confirmed the use of chitin nanofibers and cellulose nanocrystals. The maximum sorption capacity of CNCs was $2.5 \mathrm{mg}$ $\mathrm{g}^{-120}$ and chitin nanofibers was $141.08 \mathrm{mg} \mathrm{g}^{-1} \cdot{ }^{21}$ TEMPO-CNF were also used for the bioremediation of copper ions; 44.2$135 \mathrm{mg} \mathrm{g}^{-1}$ sorption capacity was reported with varying carboxylic group contents $\left(0.6-1.5 \mathrm{mmol} \mathrm{g}^{-1}\right) .{ }^{22,23}$ Our finding confirms the outstanding functionality of the used nanocellulose; the $\mathrm{PCNC}_{\mathrm{SL}}$ has the highest $\left(233 \mathrm{mg} \mathrm{g}^{-1}\right) \mathrm{Cu}$ adsorption followed by $\mathrm{CNC}_{\mathrm{BE}}\left(64 \mathrm{mg} \mathrm{g}^{-1}\right)$.

The sorption capacity of $\mathrm{Fe}^{3+}\left(512 \mathrm{mg} \mathrm{g}^{-1}\right)$ is very high for PCNC $_{\mathrm{SL}}$ membranes in cross-flow mode. One very interesting literature report shows the use of cow bone charcoal for the removal of iron metal ions from industrial wastewater ${ }^{24}$ but the sorption capacity of used adsorbent was very low $\left(31.4 \mathrm{mg}^{-1}\right)$ compared to $\mathrm{PCNC}_{\mathrm{SL}}\left(512 \mathrm{mg} \mathrm{g}^{-1}\right)$ and also $\mathrm{CNC}_{\mathrm{BE}}\left(102 \mathrm{mg} \mathrm{g}^{-1}\right)$ from the current study.

$\mathrm{The} \mathrm{g}^{+}$sorption capacity onto the with respect to unit mass of our bi-layered membrane or functional entity was lower compared to adsorption results reported by Herrera et al. ${ }^{25}$ on the alfalfa biomass $\left(27.37 \mathrm{mg} \mathrm{g}^{-1}\right)$ and other available resins; Duolite GT-73 (155.92 $\mathrm{mg} \mathrm{g}^{-1}$ ), Diaion WT01S (45.0 $\mathrm{mg} \mathrm{g}^{-1}$ ), Diaion CRB02 (15.83 $\left.\mathrm{mg} \mathrm{g}^{-1}\right)$ and Dowex $66\left(48.44 \mathrm{mg} \mathrm{g}^{-1}\right)^{3,25}$ (See Table 3). The main reason is the low initial concentration of $\mathrm{Ag}^{+}$where as the adsorption capacity reported in the literature is at the saturation limit.

It is expected that the membranes can be reused after the recovery of the heavy metal ions by acid wash or incinerated at the end-of-life to recover metal ions. It is also considered that these biobased membranes after adsorption of $\mathrm{Ag}^{+}$ions can be converted to an antibacterial device for the treatment of drinking water as reported by Theresa et al. ${ }^{26}$ The reuse of $\mathrm{Ag}^{+}$ ions adsorbed membranes, as antibacterial device will be reported in future.

\subsection{Mechanism of metal ion removal from water}

The bi-layered membranes samples, before and after incubating with effluent water were used for elemental constitution analysis and the spectrum is shown in Fig. 6. Only Si, S, C and $\mathrm{O}$ can be observed in untreated ones which have been known as the principle elements of fabricated membranes. No signals of $\mathrm{Ag}^{+}, \mathrm{Cu}^{2+}$ and $\mathrm{Fe}^{3+} / \mathrm{Fe}^{2+}$ elements were found in this spectrum. The EDS spectrums of membranes treated with contaminated water show the introduction of new peaks, which confirms the presence of the respective metal ions on

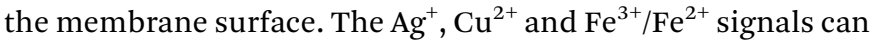
be observed on the spectrum obtained after treatment with polluted water, indicating that the interaction/immobilization of metal pollutants had occurred on the surface of fabricated 
Table 3 Comparison of sorption capacity of used nanocellulose membranes with other adsorbents ${ }^{a}$

Sorption capacity of used nanocellulose membranes Maximum sorption capacity of reference adsorbents (from adsorption isotherm modeling) Ion $\left(\mathrm{mg} \mathrm{g}^{-1}\right) \quad \mathrm{CNC}_{\mathrm{SL}} \quad \mathrm{CNC}_{\mathrm{BE}} \quad \mathrm{P}_{-\mathrm{CNC}} \mathrm{SL}_{\mathrm{SL}}$ Alfalfa biomass $\quad$ Cow bone charcoal Chitosan CNCs Chitin fibers CNT TEMPO CNF Ref.

\begin{tabular}{|c|c|c|c|c|c|c|c|c|c|c|c|}
\hline $\mathrm{Ag}^{+}$ & 0.42 & 0.87 & 1.0 & 27.37 & - & - & 34.4 & - & & & 3 and 25 \\
\hline $\mathrm{Cu}^{2+}$ & 11 & 67 & 358 & - & - & 70 & 2.5 & 141.08 & 67.8 & $44.2-135$ & $18-23$ \\
\hline $\mathrm{Fe}^{3+} / \mathrm{Fe}^{2+}$ & 20 & 102 & 512 & - & 31 & 14 & - & - & & & 18 and 24 \\
\hline
\end{tabular}

${ }^{a}$ The values reported in the literature are the saturation limit (determined after 10 to 15 cycle of reuse) but in our study only one cycle of adsorption evaluation was performed. Thus, the reusability must be performed in future to find the saturation limit.

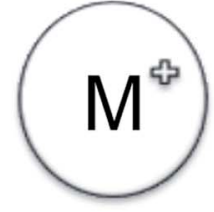

a
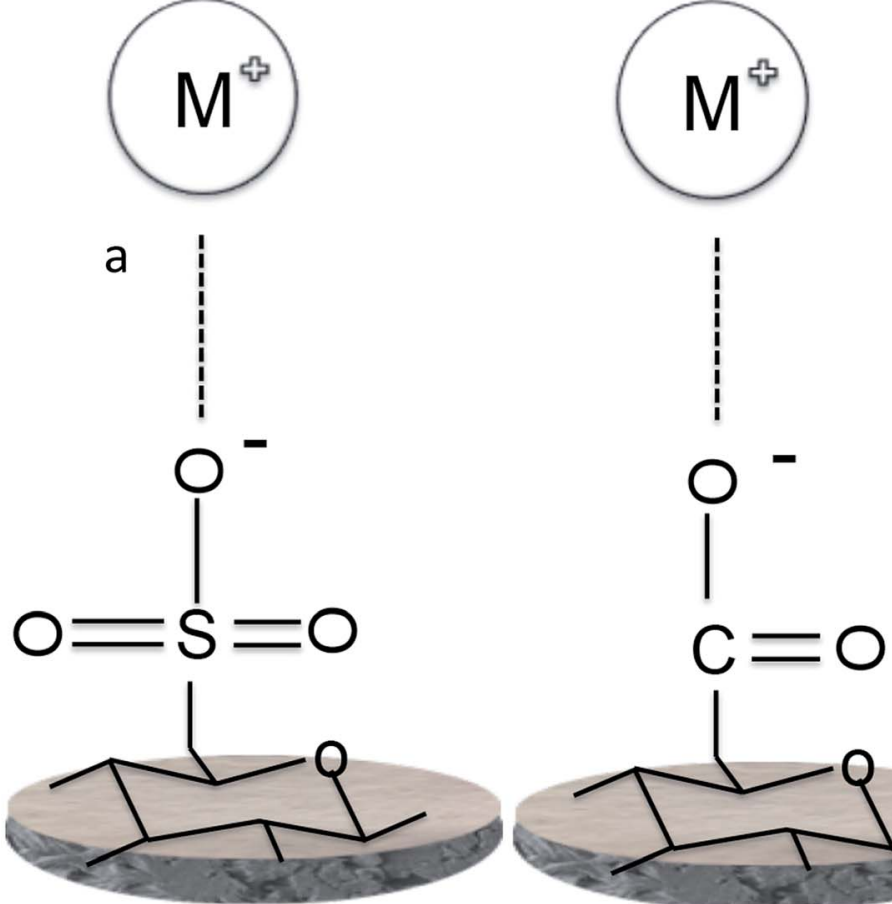

S-G/CNC $\mathrm{SL}$

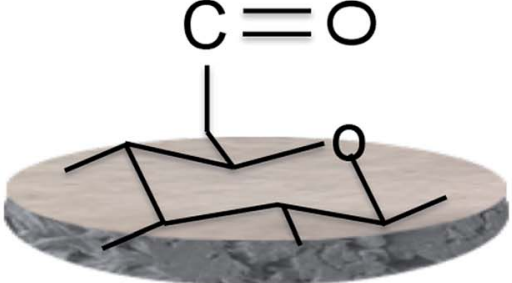

S-G/CNC $C_{B E}$

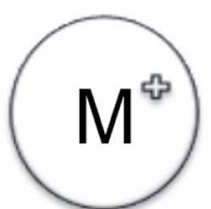

!
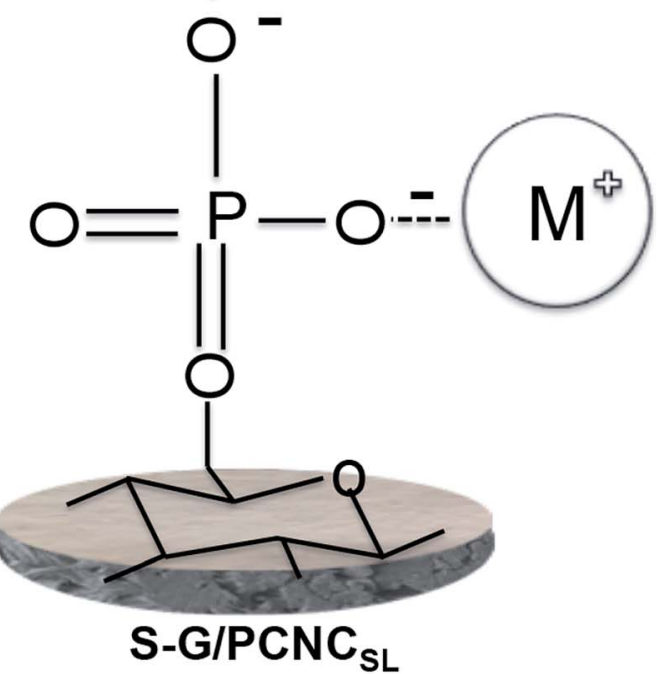

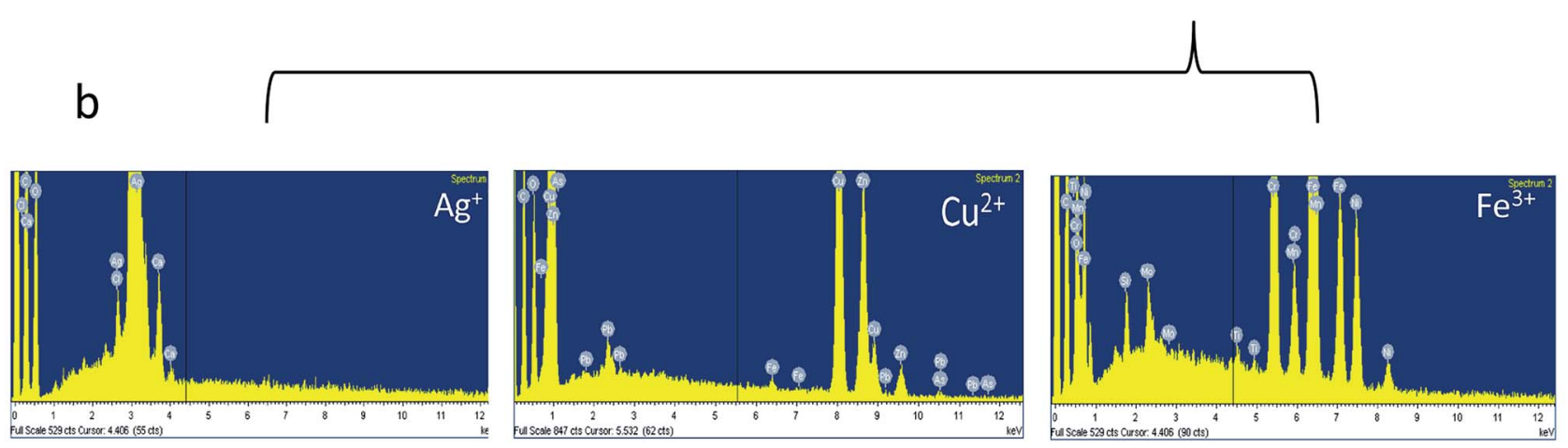

Fig. 6 Proposed mechanism for the metal ions adsorption (a) and a confirmation with EDS (b). The EDS results are shown only for S-G/PCNC $\mathrm{SL}_{\mathrm{S}}$ nanocomposite membranes and the same pattern have been observed with other two membranes. The scanning area of samples analysed by EDS was $200 \mu \mathrm{m}^{2}$ and samples were not smooth due to adsorption of heavy metals on the surface of nanocomposite membranes. Thus, the results reported here are qualitative.

functional nanocellulose. Our results are in the agreement with previously published data regarding $\mathrm{Cu}^{2+}$ adsorption on the surface of iron-coated sand. ${ }^{27}$
The possible mechanism for the adsorption of metal ions on the surface of fabricated nanocomposite might be electrostatic interactions, ions exchange, microprecipitation or interaction 


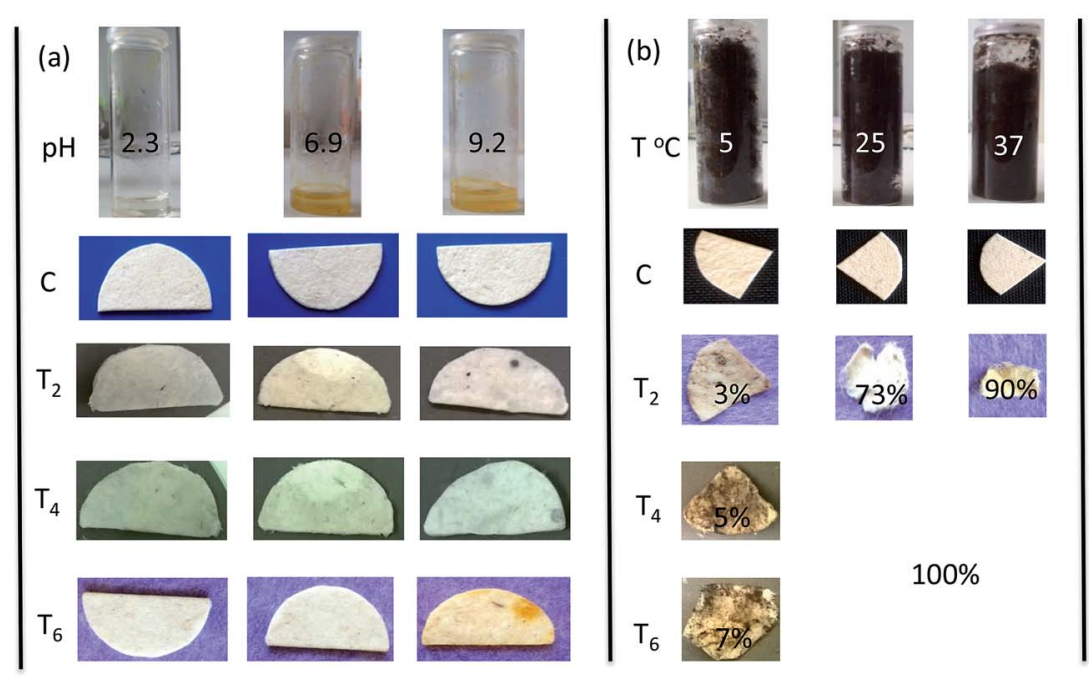

Fig. 7 Stability/biodegradation test of support- $\mathrm{CNC}_{\mathrm{BE}}$ nanocomposite membranes in real wastewater (a) and soil (b). Nanocomposite membranes have been incubated as discussed in manuscript, percentage degradation was calculated using control samples as $100 \%$. $C, T_{2}, T_{4}$ and $T_{6}$ denotes incubation time interval as $0,2,4$ and 6 months.

followed by nucleation effect. The mechanisms are not fully understood and interactions as shown in Fig. 6a can be expected. The existences of functional entities as phosphate, carboxylic and sulphonate, on macromolecules chain of $\mathrm{PCNC}_{\mathrm{SL}}, \mathrm{CNC}_{\mathrm{BE}}$ and $\mathrm{CNC}_{\mathrm{SL}}$, respectively are the main driving force for negative charges on nanocellulose. ${ }^{6}$ The isolation of $\mathrm{CNC}_{\mathrm{SL}}$ was performed by sulphuric acid hydrolysis ${ }^{8}$ and presence of sulfonate groups $\left(\mathrm{SO}_{3}{ }^{-}\right)$was confirmed by FTIR in our previous study. ${ }^{14}$ The main functional group available on $\mathrm{CNC}_{\mathrm{BE}}$ after isolation process was carboxylate $\left(-\mathrm{C}=\mathrm{OO}^{-}\right)$and is confirmed by XPS analysis ${ }^{14}$ PCNC $_{\mathrm{SL}}$ was highly effective for metals ions removal and is due to the introduction of phosphate $\left(\mathrm{PO}_{3}{ }^{2-}\right)$ group on the surface of $\mathrm{CNC}_{\mathrm{SL}}$ during hexokinasemediated reaction, as described previously. ${ }^{14,15}$ See ESI S2 $\uparrow$ for the IR spectrum of the used functional entities.

The results are also agrees with our earlier studies where model and industrial waste water contaminated with heavy metals ions has treated with four nanocellulose functional entities; $\mathrm{CNC}_{\mathrm{SL}}, \mathrm{CNC}_{\mathrm{BE}}$, P-CNC and P-CNF. ${ }^{6}$ It is worth noticing that the fabrication of these nanoparticles in membranes provides the possibility to use them in cross-flow mode, which further enhances the removal efficiency towards metal ions.

\subsection{Membrane stability/biodegradability study}

The visual illustrations of membranes during different stages of degradation the effluent as well as soil are shown in Fig. 7. In the case of effluent water (Fig. 7a) with metal ions and with different $\mathrm{pH}$ conditions, no degradation was noted with respect to weight loss or visual appearance, up to 6 months. However the samples showed a change in color attributable to be the adsorption of metal ions/contaminants present in wastewater. Biodegradability of fabricated membranes is depends on weight/size of used membranes, composition of membranes and the effect of living or dead organism. The used wastewater from mining industry was not a suitable habitat for microorganisms to grow. Therefore, the membranes were stable in real polluted water up to 6 months and confirm the suitability of these membranes in real water purification system.

In the case of degradation studies in soil at different temperatures, a different trend was observed. The soil structure and composition (mineral and organic), temperature, water activity, $\mathrm{pH}$, and the oxygen and carbon dioxide content affect degradation. Therefore the extent of biodegradation of the membranes can be expected to vary with region and from season to season. Moreover degradation by microbial attack is the major mode of degradation of the natural composites in soil. In this study, all the above-mentioned factors were maintained uniform for all the samples and degradation studies were carried out under laboratory conditions. The membranes degraded rapidly in soil confirmed by weight loss as well as via visual appearance (see Fig. 7b). It was observed that at higher temperature degradation occurred at higher rates. Complete degradation of $\mathrm{CNC}_{\mathrm{BE}}$ membrane was recorded after four months of incubation. Our results are also agreement with previous published data, where cellulose film was incubated with soil having fungus microbes. A porous structure with fungal mycelia on the surface of the decayed film was observed, indicates microbial degradation of cellulose film. ${ }^{28}$

\section{Conclusions}

The study demonstrates the successful processing and utilization of fully biobased cellulose nanocomposite membranes for metal ions capture from industry effluents. We report for the first time, high flux layered cellulose membranes with nanocellulose composite as functional layer, prepared following a very simple, fast and effective process, viz. vacuum filtration followed by hot pressing. The support layer provided mechanical stability to the membrane while the functional layer immobilized metal ions from contaminated water via 
adsorption. The porous network of microfibers with a thin functional layer of nanocellulose resulted in high flux and maximal functionality. Good mechanical stability in wet conditions; favorable pore structure and water permeability as well as high affinity of the developed membranes towards metal ions indicate promising new technology for green water purification technology. PCNC $_{\mathrm{SL}}$ based membranes were most effective for the removal of all three metal ions and the adsorption capacity after single cycle of cross-flow filtration was higher than reference adsorbents found in literature. Biodegradation studies in effluent water and soil indicates the potential of these membranes in real application where long term membrane performance in use conditions and possible biodegradation at end-of-life are crucial economical, efficient and environmental friendly membranes.

\section{Acknowledgements}

The authors gratefully acknowledge the financial support by European Commission, under NanoSelect project, EU FP7NMPA-SL-2012-280519. Iftekhar Uddine Bhuiyan, Luleå University of Technology, is acknowledged for SEM results.

\section{Notes and references}

1 R. K. Rattan, S. P. Datta, P. K. Chhonkar, K. Suribabu and A. K. Singh, Agric., Ecosyst. Environ., 2005, 109, 310-322.

2 B. R. Mattuschka, G. Junghans and A. Stmbe, Bio-sorption of metals by waste biomass, biohydrometalurgical technology, Proceeding of International Biohydrometalurgy Symposium, Jachson Hole, Wyoming, USA, 1993.

3 M. Min, L. Shen, G. Hong, M. Zhu, Y. Zhang and X. Wang, Chem. Eng. J., 2012, 197, 88-100.

4 H. Ma, C. Burger, B. S. Hsiao and B. Chu, J. Mater. Chem., 2011, 21, 7507-7510.

5 H. Ma, C. Burher, B. S. Hsiao and B. Chu, Biomacromolecules, 2012, 13, 180-186.

6 P. Liu, P. Ferrer, K. Oksman, M. Bozic, V. Kokol and A. P. Mathew, J. Hazard. Mater., 2015, 294, 177-185.

7 P. Liu, H. Sehaqui, P. Tingaut, A. Wichser, K. Oksman and A. P. Mathew, Cellulose, 2014, 21, 449-461.

8 K. Karim, A. P. Mathew, A. Grahn, J. Mouzon and K. Oksman, Carbohydr. Polym., 2014, 112, 668-676.

9 H. Sehaqui, U. P. deLarraya, P. Tingaut and T. Zimmermann, Soft Matter, 2015, 11, 5294-5300.
10 M. Henriksson, L. A. Berglund, P. Isaksson, T. Lindstrom and T. Takashi Nishino, Biomacromolecules, 2008, 9, 15791585.

11 H. Sehaqui, Q. Zhou, O. Ikkala and L. A. Berglund, Biomacromolecules, 2011, 12, 3638-3644.

12 A. Mautner, K. Y. Lee, T. Tammelin, A. P. Mathew, A. J. Nedoma, K. Li and A. Bismarck, React. Funct. Polym., 2015, 86, 209-214.

13 A. Mautner, H. A. Maples, S. Houssine, T. Zimmermann, U. P. De Larraya, A. P. Mathew, C. Y. Lai, K. Li and A. Bismarck, Environ. Sci.: Water Res. Technol., 2016, 2, 117-124, DOI: 10.1039/c5ew00139k.

14 A. P. Mathew, K. Oksman, Z. Karim, P. Liu, S. A. Khan and N. Naseri, Ind. Crops Prod., 2014, 58, 212-219.

15 M. Bozic, L. Peng, A. P. Mathew and V. Kokol, Cellulose, 2014, 21, 2713-2726.

16 C. Visvanathan, B. R. Aim and K. Parameshwaran, Crit. Rev. Environ. Sci. Technol., 2000, 30, 1-48.

17 A. Theresa, G. Dankovich and D. G. Gray, Environ. Sci. Technol., 2011, 45, 1992-1998.

18 F. Takeshi, K. Matsushima and K. I. Kikuchi, Chemosphere, 2014, 55, 135-140.

19 A. Gadhave and J. Waghmare, Int. J. Chem. Sci. Appl., 2014, 5, 56-67.

20 H. Lu, Y. Gui, L. Zheng and X. Liu, Food Res. Int., 2013, 50, 121-128.

21 D. Liu, Z. Ti, L. Zehui, T. Donglin and C. Lie, Carbohydr. Polym., 2013, 98, 483-489.

22 H. Sehaqui, U. P. de-Larraya, P. Liu, N. Pfenninger, A. P. Mathew, T. Zimmermann and P. Tinguat, Cellulose, 2014, 21, 2832-2844.

23 P. Liu, K. Oksman, A. P. Mathew and J. Collo, Int. Sci., 2016, 464, 175-182.

24 J. Monreno, C. Gomez, L. Rigoberto and L. Giraldo, Materials, 2010, 2, 452-466.

25 I. Herrera, J. L. Gardea-Torresdey, K. J. Tiemann, J. R. Peralta-Videa, V. Armendariz and J. G. Parsons, J. Hazard. Subst. Res., 2003, 4, 1-15.

26 A. Theresa, D. Dankovich and G. Gray, Environ. Sci. Technol., 2011, 45, 1992-1998.

27 C. H. Lai, S. L. Lo and H. L. Chiang, Chemosphere, 2000, 41, 1249-1255.

28 H. Qi, C. Chunyu and L. Zhang, Green Chem., 2009, 11, 177184. 